University of Nebraska - Lincoln

DigitalCommons@University of Nebraska - Lincoln

Faculty Publications, Department of Psychology

Psychology, Department of

$2-1-2000$

\title{
The Differential Relations of Parent and Peer Attachment to Adolescent Adjustment
}

\author{
Deborah J. Laible \\ University of Nebraska-Lincoln, del205@lehigh.edu \\ Gustavo Carlo \\ University of Nebraska-Lincoln, carlog@missouri.edu \\ Marcela Raffaelli \\ University of Nebraska-Lincoln, mraffaelli1@unl.edu
}

Follow this and additional works at: https://digitalcommons.unl.edu/psychfacpub

Part of the Psychiatry and Psychology Commons

Laible, Deborah J.; Carlo, Gustavo; and Raffaelli, Marcela, "The Differential Relations of Parent and Peer Attachment to Adolescent Adjustment" (2000). Faculty Publications, Department of Psychology. 51. https://digitalcommons.unl.edu/psychfacpub/51

This Article is brought to you for free and open access by the Psychology, Department of at DigitalCommons@University of Nebraska - Lincoln. It has been accepted for inclusion in Faculty Publications, Department of Psychology by an authorized administrator of DigitalCommons@University of Nebraska - Lincoln. 
Published in Journal of Youth and Adolescence 29:1 (February 2000), pp. 45-59.

Copyright (C) 2000 Springer Verlag. Used by permission. DOI 10.1023/A:1005169004882

Online link $=\underline{\mathrm{http}}: / / \mathrm{www}$. springerlink.com/content/14814t561117k76u

\title{
The Differential Relations of Parent and Peer Attachment to Adolescent Adjustment *
}

\author{
Deborah J. Laible, ${ }^{1}$ Gustavo Carlo, ${ }^{2}$ and Marcela Raffaelli ${ }^{3}$ \\ Submitted April 1998; accepted October 1999
}

\begin{abstract}
Whether or not close emotional relationships with parents and peers serve similar functions for adolescent adjustment is an issue of increasing interest. The present study was designed to examine the relations between parent and peer attachment and adolescent adjustment. Eighty-nine adolescents ( $M$ age $=16.1$ years, $S D=1.8$ years) completed self-report measures of parent and peer attachment, sympathy, academic efficacy, aggression, anxiety, and depression. Adolescents were divided into four groups on the basis of their parent and peer attachment scores: those high on both, those low on both, those high on peer but low on parent attachment, and those high on parent but low on peer attachment. Discriminant function analyses revealed that the groups differed only along one dimension, suggesting that parent and peer attachment served similar functions in terms of the adjustment indices measured. Adolescents high on both peer and parent attachment were the best adjusted (i.e., least aggressive and depressed, most sympathetic) and those low on both were the least well adjusted. Furthermore, those high on peer but low on parent attachment were better adjusted than those high on parent but low on peer attachment, suggesting that peer attachment may be relatively more influential on adolescent adjustment than parent attachment.
\end{abstract}

* The authors appreciate the assistance of Clarrisa Bendezu, Sue Cain, Roxana Carlo, Randy Ernst, Alix Gomez, Marcia Kohler, Neil Nicolaus, Veronica Palomo, Lorena Pulgarin, Alicia Spilker, and Ellen Wilson. We also wish to thank the staff at the Hispanic Community Center and the students, parents, staff, and teachers of the participating schools. This project was supported by a grant from the Institute for Ethnic Studies and by Summer Faculty Fellowships from the Office of the Research Council to Marcela Raffaelli and Gustavo Carlo.

\footnotetext{
${ }^{1}$ Fifth-year doctoral student in developmental psychology at the University of Nebraska-Lincoln. Her current research interests focus on parent-child attachment, parent-child conflict, and socioemotional development. To whom correspondence should be addressed at Department of Psychology, University of Nebraska, Lincoln, Nebraska 68588-0308. e-mail: dlaible@unlserve.unl.edu.

${ }^{2}$ Assistant Professor at the University of Nebraska-Lincoln. His research interests focus on prosocial and moral development.

${ }^{3}$ Associate Professor at the University of Nebraska. Her research interests focus on the developmental impact of homelessness, parent-child communication about sexual issues, and cultural influences on sexuality.
} 


\section{INTRODUCTION}

Although it is no longer accepted that adolescence is a period of intense turmoil as in popular portrayals, adolescence is still considered an important transition period, because of the cognitive, biological, and social changes that occur during this time period (Elliot and Feldman, 1990). Furthermore, research does indicate that adolescence is a period of heightened risk; rates of depression, conduct disorders, suicide, and drug and alcohol use increase across adolescence (Adams and Gullotta, 1989). While the vast majority of adolescents navigate this transitional period with much success, happiness, and confidence, a significant minority of adolescents experience much uncertainty and distress (Cauce et al., 1994). One important factor that distinguishes adolescents who navigate the transition with success and those who do not is the quality of relationships that the adolescent has with both parents and peers.

Traditionally, adolescence was viewed as a period of life in which the support of the peer group gradually usurped the influence of parents, mostly as the result of intergenerational conflict over fundamental values, norms, and behaviors (Coleman, 1961). Research has not supported the idea that parents and adolescents engage in conflict over such issues, however, and in fact has suggested that much continuity may exist in parent-child relationships across middle childhood and adolescence (see Grotevant, 1997). Despite their growing reliance on peers for support, the vast majority of adolescents continue to rely on their parents for emotional support and advice (Maccoby and Martin, 1983). For example, in a study of 2800 adolescents between 12 and 15 years of age, a large majority of the participants named parents as having an important and significant positive influence on their lives (Blyth et al., 1982). Therefore, adolescence is now conceptualized as a period of both growing autonomy and connectedness to parents and other significant adults.

The idea that parents continue to be influential in providing support during adolescence has been strengthened by the growing interest in applying attachment theory to areas of the life span beyond infancy. Attachment was originally defined as the strong affective bond established between the infant and the primary caregiver (generally the mother) (Bowlby, 1973, 1982). However, in recent years attachment has been reconceptualized to include all significant relationships across the life span including those with peers and romantic partners (e.g., Armsden and Greenberg, 1987; Hazan and Shaver, 1987; Kobak and Cole, 1994; Kobak and Sceery, 1988). A central feature of attachment theory is the notion that children are constructing models of relationships out of interactions with attachment figures (Bowlby, 1980, 1982). These models include expectations about the attachment figure's responsiveness and accessibility, as well as the self's deservingness of such care (Ainsworth, 1989; Bowlby, 1980; Bretherton, 1990). Although internal working models are open to reformulation across development, according to Bowlby (1980), they tend to persist across time and significantly influence the manner in which the child construes 
the self and others within the context of interpersonal relationships. Thus, attachment theory holds that attachments to parents and the internal working models of these relationships continue to be influential into adolescence and adulthood, even if a new primary attachment figure replaces the parent (Ainsworth, 1989). Research has supported the continued influence of attachment bonds to parents in adolescence. Studies have shown that a secure attachment with parents in adolescence predicts higher self-esteem, greater life satisfaction, better college adjustment, less psychological distress, and greater perceived social support (Armsden and Greenberg, 1987; Blain et al., 1993; Bradford and Lyddon, 1993; Lapsley et al., 1990).

Attachment theory has particularly interesting applications for understanding adolescent development, because it is during this time that children explore intimate, supportive relationships outside of the family. Despite this, however, researchers have only recently begun to show an interest in the functions that attachments to others than parents might serve during adolescence (e.g., Armsden and Greenberg, 1987; Hazan and Shaver, 1987). Research into the role of peers as attachment figures is lacking, despite the fact that research from the friendship and support literature has supported the idea that close relationships with peers promote healthy adolescent adjustment. Strong relationships with peers has been linked with perceived self-worth (Robinson, 1995), high levels of perspective taking and prosocial behavior (Azmitia and Perlmutter, 1989; Eisenberg and Fabes, 1997), and decreased risk of emotional and behavioral problems (Cauce et al., 1994; Garneski and Diekstra, 1996; Coie and Dodge, 1997).

It is clear that supportive relationships with both parents and peers play an important role in an adolescent's adjustment. One as yet unanswered question is whether peers and parents play similar or unique roles in adolescent development and adjustment. Some scholars (e.g., Piaget, 1965; Youniss, 1980) have argued for the uniqueness of peer relationships, suggesting that peer friendships are marked by mutual reciprocity and cooperation, unlike parentchild relationships, which are based more on unilateral power and are more likely to involve obedience and conformity. According to these theorists, peer relationships play a unique role in an adolescent's development because they are likely to involve coconstructions of reality, negotiation, and working toward a consensus. For example, Piaget (1965) suggested that peer interactions stimulate moral development, because peers provide a haven in which individuals can experiment with minimal risk to self-concept.

Other researchers have questioned whether parent-child relationships are best characterized in terms of power (see Kuczynski et al., 1997). Both parents and children are involved in an intimate relationship with each other and each partner is both powerful and vulnerable relative to the other (Kuczynski et al., 1997). These researchers propose that parent-child relationships are characterized both in terms of friendship and in terms of an authority relationship. As a result, the parent-child relationship may be better thought of 
as a "mixed relationship," or a mixture of horizontal and vertical power relationships (Laursen and Collins, 1994). Furthermore, evidence suggests a considerable amount of overlap in peer and parent relationships. Both parents and peers provide emotional support and intimacy during adolescence and in nomination tasks, parents and peers receive equal numbers of nominations as primary support figures throughout adolescence (Freeman, 1997).

The goal of the current research was to investigate whether parents and peers serve similar functions in adolescent adjustment. The current analysis was designed to examine the relations between concurrent parent and peer attachment and a variety of adolescent adjustment indices, including depression, anxiety, aggression, sympathy, and academic efficacy. Previous research has linked these adjustment indices to the quality of either peer or parent relationships (e.g., Armsden and Greenberg, 1987; Azmitia and Perlmutter, 1989; Belsky and Pensky, 1988; Bradford and Lyddon, 1993; Demo and Acock, 1996; Dodge, 1997; Garnefski and Diekstra, 1996; Laible and Thompson, 1999; Melby and Conger, 1996; Ryan et al., 1994) but has not compared the influence of parent and peer attachment. Because research is unclear about the extent to which parent and peer relationships serve similar functions, no specific a priori hypotheses were formed. In general, however, it was expected that high levels of both parent and peer attachment would be associated with positive adolescent adjustment. Thus, it was predicted that adolescents with secure relationships with both parents and peers would show the most positive adjustment and those with less secure relationships with both would show the least positive adjustment.

\section{METHOD}

\section{Recruitment and Procedures}

Participants were 89 (46 females, 43 males) students were from one public middle school and one public high school in a midsized Midwestern city $(\mathrm{M}$ age $=16.0$ years, $\mathrm{SD}=1.81$ years $)$. Fifty-three percent were of EuropeanAmerican origin, 38\% were of Latino origin, and 9\% were of other ethnic origins. Recruitment letters were sent to parents with the cooperation of school personnel, and parent consent and student assent were obtained prior to participation. Surveys were administered in small groups in a separate classroom during school hours and took approximately forty minutes to an hour to complete. Participating classrooms received small monetary donations.

\section{Measures}

The surveys consisted of a number of demographic items and a battery of scales. All of the scales (except for the math and English efficacy scales) had been previously used with adolescents. Demographic items included ques- 
tions about the parents' level of education (average of mother's and father's education, $\mathrm{M}=3.5, \mathrm{SD}=1.8$, on a 7 -point scale where $3=$ some college or technical school and $4=$ graduated from 2-year college or technical school). The survey also included the following scales:

Parent and Peer Attachment. Students completed a shortened version of the Inventory of Parent and Peer Attachment (Armsden and Greenberg, 1987). The original scale was developed and tested with adolescents and was designed to assess both the affective and cognitive dimensions of attachment security and trust in the accessibility and responsiveness of attachment figures. Both the shortened parent and peer scales consisted of 12 items (in the present study, parent $\alpha=.85$ and peer $\alpha=.84$ ), four from each of the three original subscales, i.e., trust, communication, and alienation. Parallel peer and parent items were chosen (sample item, "My parent respects my feelings," "My friends respect my feelings"). Both scales were rated on a 5-point scale from never to always. For the parent scale participants were instructed that if they had a different relationship with their mother and father, they should respond to the items for the parent who most influenced them.

Depression. Depression was assessed with the use of the Child Depression Inventory (Kovacs and Beck, 1977). The scale consisted of 26 items (the suicide ideation item was dropped) and had a reliability of $\alpha=.84$ in the present study.

Sympathy. Students completed the empathic concern and perspective taking subscales from the Interpersonal Reactivity Questionnaire (Davis, 1983). Both the empathic concern scale ( $\alpha=.79$ in the present study) (sample item, "I often have tender, concerned feelings for people less fortunate than me") and the perspective taking scale ( $\alpha=.71$ in the present study) (sample item, "I sometimes find it difficult to see things from the 'other person's' point of view") consisted of seven items. Both scales were rated on a 5-point scale ranging from "does not describe me" to "describes me very well."

Because perspective taking and empathic concern are theoretically and empirically related (Davis, 1983), a sympathy scale was formed by combining the two scales. Preliminary correlational analysis indicated that the empathic concern and perspective taking scales were significantly interrelated $[\mathrm{r}(89)$ $=.61, \mathrm{p}<.001]$ and thus the two scales were summed and averaged to form a sympathy scale ( $\alpha=.85$ in the present study).

Anxiety. Anxiety was assessed using a shortened 14-item version of the Revised Childhood Manifest Anxiety Scale (Reynolds and Richmond, 1985). The shortened scale had a reliability of $\alpha=.85$ (in the present study) and students were asked to rate items (e.g., "My hands feel sweaty" and "I am nervous") on a 5-point scale from "never" to "always."

Aggression. Aggression was measured by combining the Suppression of Aggression subscale from the Weinberger (1991) Adjustment Inventory and the following two fighting items: "During the past year, how many times 
were you in a physical fight in which weapons were present?" and "When no weapons were present?" The Suppression of Aggression scale was rated on a 5-point Likert scale and consisted of five items (sample item, "I lose my temper and 'let people have it' when I'm angry"). For the fighting items, students were asked to select from between 0 to 12 or more times. Both the Suppression of Aggression scale $(\alpha=.84)$ and the two fighting items $(\alpha=.89)$ were converted to Z-scores and then summed to form a seven-item index of aggression $(\alpha=.83)$.

Math and English Efficacy. Students rated eight questions concerning math and English academic efficacy on a 5-point scale (ranging from "not very good/one of the worst" to "very good/very well/one of the best"). Each scale consisted of the following four questions (parallel for math and English): (a) How good are you at math/English? (b) Compared to other students, how good are you at math/English? (c) How well do you expect to do in math/ English this year? and (d) How good would you be at learning something new in math/English? Reliabilities for each scale were good ( $\alpha$ for English $=$ .88 and $\alpha$ for math $=.91$ ).

\section{RESULTS}

\section{Descriptive and Preliminary Analyses}

Means, standard deviations, and ranges for all variables used in this analysis appear in Table I. In addition, correlations were calculated to examine the relations between parent and peer attachment and the adjustment indices (Table II). Parent attachment was significantly related to age, depression, and aggression. Adolescents who were older reported lower levels of parent attachment. In addition, adolescents who reported higher levels of parent attachment reported lower levels of both aggression and depression. Peer attachment was significantly related to sympathy, English efficacy, depression and aggression. Adolescents who reported higher levels of peer attachment also reported higher levels of sympathy and English efficacy and lower levels of depression and aggression. Other significant correlations were also found (e.g., sympathy correlated negatively with aggression) and these are listed in

Table I. Descriptive Statistics for Parent and Peer Attachment and Adjustment Variables

\begin{tabular}{lrrr}
\hline \multicolumn{1}{c}{ Variable } & Mean & SD & Range \\
\hline Peer attachment & 3.68 & .62 & $1.83-4.83$ \\
Parent attachment & 3.51 & .79 & $1.58-5.58$ \\
Sympathy & 3.58 & .65 & $1.29-4.71$ \\
Depression & .40 & .24 & $.04-1.15$ \\
Anxiety & 2.52 & .76 & $1.00-4.80$ \\
Aggression & 2.53 & 1.06 & $1.00-5.00$ \\
English efficacy & 3.92 & .86 & $2.00-5.00$ \\
Math efficacy & 3.66 & 1.06 & $1.00-5.00$ \\
\hline
\end{tabular}




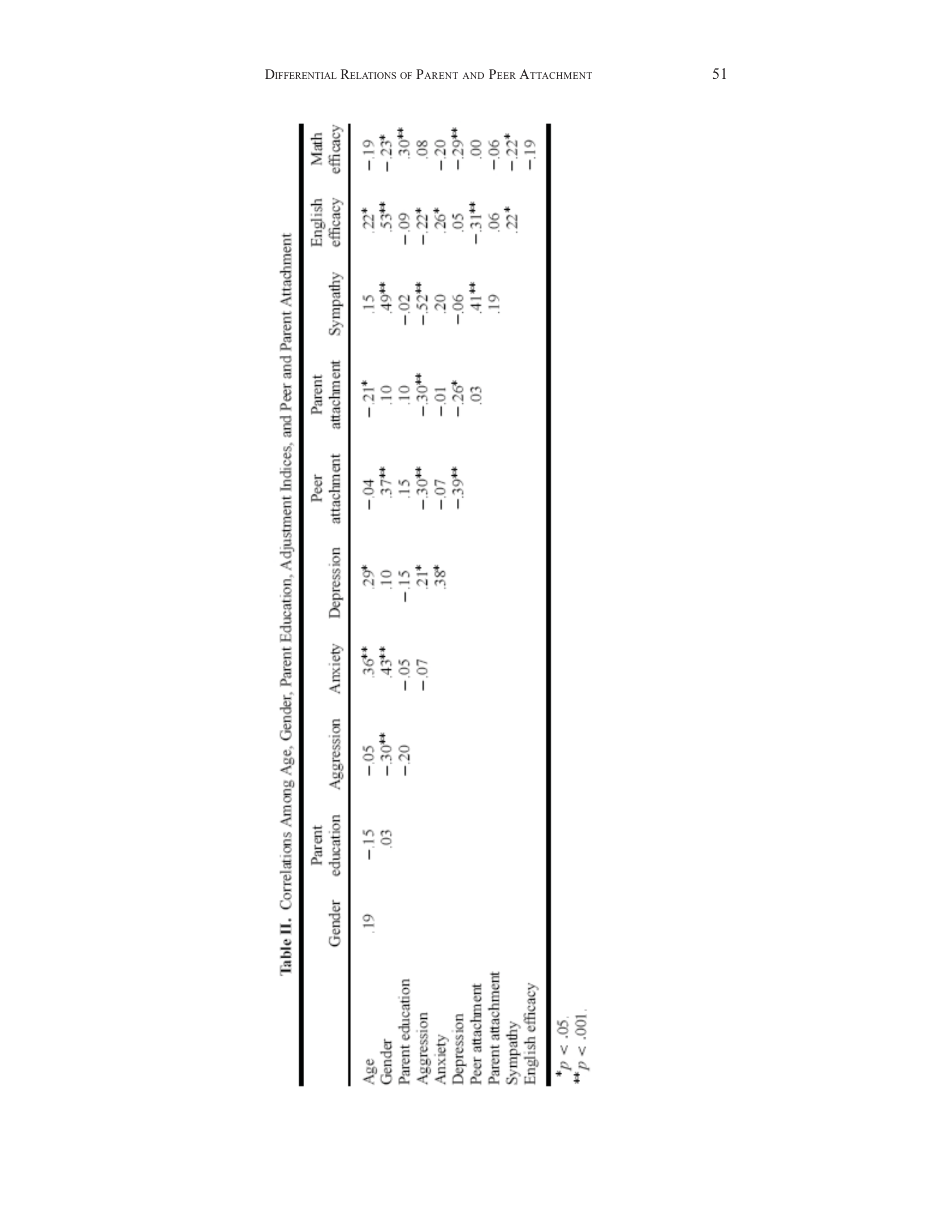


Table II. Because age, gender, and parent education were significantly related to adolescent adjustment indices, these variables were included in subsequent analyses.

\section{Relations of Parent and Peer Attachment to Adolescent Adjustment}

To examine the relations of parent and peer attachment to adjustment, the adolescents were divided into four groups based on their parent and peer attachment scores: those above the mean on both scales $(\mathrm{N}=21)$, those below the mean on both scales $(\mathrm{N}=17)$, those above the mean on peer but below the mean on parent attachment $(\mathrm{N}=24)$, and those above the mean on parent but below the mean on peer attachment $(\mathrm{N}=27)$. A linear discriminant function was built to determine if the four groups could be differentiated in terms of age, gender, parent education, depression, aggression, anxiety, sympathy and English and math efficacy.

Multivariate analysis revealed that the first discriminant function reliably differentiated among the four groups of adolescents $\left(\lambda=.43, \chi^{2}=63.5, \mathrm{p}\right.$ $<.001)$ but that the second and third functions did not provide further differentiation. Using the linear discriminant functions, $57.0 \%$ of the adolescents were correctly reclassified against the chance level of $28.2 \%$. A standard cutoff of $>.3$ (see Tabachnick and Fidell, 1996) was applied to the structure weights to determine which variables contributed to discrimination between the four groups. Examination of the structure weights (see Table III) revealed that depression, aggression, gender, and sympathy contributed to the discrimination between groups. A graphical depiction of the model appears in Fig. 1. The group with high scores on both parent and peer attachment were typically female, had the lowest scores on depression and aggression, and had the highest scores on sympathy. In contrast, adolescents with low scores on both parent and attachment were typically male, had the highest scores on depression and aggression, and had the lowest scores on sympathy. The other two groups of adolescents (i.e., those with only one secure attachment, either to a parent or to peers) had intermediate scores on depression, aggression, and

Table III. Structure Weights and Standardized Discriminant Function Coefficients $(N=89)$

\begin{tabular}{lcc}
\hline \multicolumn{1}{c}{ Variable } & Structure weight & Standardized coefficient \\
\hline Age & .14 & .10 \\
Gender & -.41 & -.53 \\
Parent education & -.22 & -.31 \\
Sympathy & -.48 & -.35 \\
Depression & .48 & .48 \\
Anxiety & .20 & .54 \\
Aggression & .48 & .22 \\
English efficacy & -.25 & -.17 \\
Math efficacy & .14 & .29 \\
\hline
\end{tabular}


Less Depressed

More Sympathetic

Less Aggressive

Female

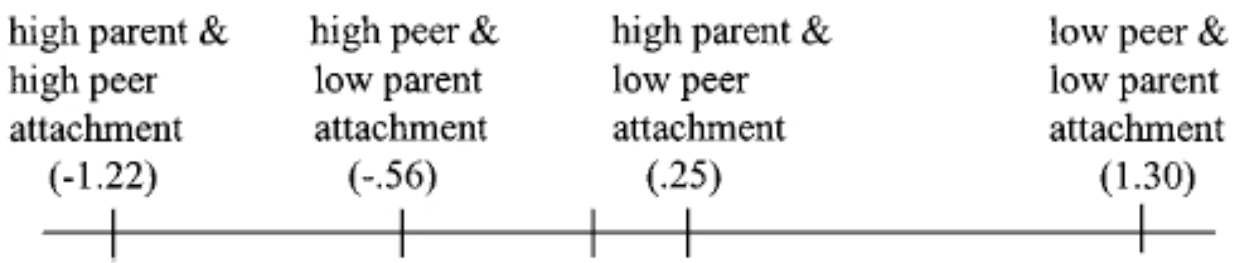

More Depressed

Less Sympathetic

More Aggressive

Male

Fig. 1. Depiction of the group means on the first function and the variables contributing to the discrimination of groups based on parent and peer attachment scores.

sympathy. However, those adolescents who reported a secure attachment to peers but not parents had slightly lower scores on depression and aggression and slightly higher scores on sympathy than those with a secure relationship to a parent but not to peers.

Examination of the standardized discriminant function coefficients (also in Table III) revealed that gender, depression, and anxiety (having a suppressor effect) made moderate independent contributions to the model. The independent contribution of aggression to the model was relatively small due to its collinearity with sympathy and gender (see Table II).

Follow-up analyses using the discriminant function scores in an ANOVA revealed significant differences between the groups $[\mathrm{F}(3,78)=22.2, \mathrm{p}<.001]$. Post hoc group comparisons using Tukey's LSD tests revealed that all four groups were significantly different from each other.

To clarify the relations between the adjustment factors (i.e., sympathy, aggression, depression, and anxiety) and attachment, separate hierarchical regression models were built to predict parent and peer attachment. Age, gender, and parent education were entered into the model in the first step as statistical controls and the adjustment indices were entered simultaneously in the second step. The regression models for both peer and parent attachment appear in Table IV. Gender, depression, English efficacy and sympathy all made significant independent contributions to the full model predicting peer attachment $[\mathrm{R} 2=.44, \mathrm{~F}(9,72)=6,30, \mathrm{p}<.001]$. Females had higher peer attachment scores than males. In addition, adolescents reporting low levels of depression were more likely to report higher levels of peer attachment, and adolescents who had higher scores on English efficacy and sympathy had higher scores on peer attachment.

In contrast, only depression made a significant independent contribution in predicting parent attachment in the full model, and the model itself was 
Table IV. Variables Predicting Peer and Parent Attachment

\begin{tabular}{|c|c|c|c|c|c|}
\hline Predictor & $\beta$ at final step & $p$ value & $R^{2}$ & $R^{2}$ change & $F$ change \\
\hline \multicolumn{6}{|c|}{ Peer attachment } \\
\hline \multicolumn{6}{|l|}{ Step 1} \\
\hline Age & -.11 & .27 & & & \\
\hline Gender & .20 & .12 & & & \\
\hline Parent education & .09 & .35 & & & \\
\hline & & & .16 & .16 & $5.12^{*}$ \\
\hline \multicolumn{6}{|l|}{ Step 2} \\
\hline Sympathy & .31 & .01 & & & \\
\hline Depression & -.28 & .01 & & & \\
\hline Anxiety & -.18 & .11 & & & \\
\hline Aggression & .00 & .97 & & & \\
\hline English efficacy & .25 & .03 & & & \\
\hline \multirow{2}{*}{ Math efficacy } & .04 & .72 & & & \\
\hline & & & .44 & .28 & $1.18^{* *}$ \\
\hline \multicolumn{6}{|c|}{ Parent attachment } \\
\hline \multicolumn{6}{|l|}{ Step 1} \\
\hline Age & -.14 & .26 & & & \\
\hline Gender & .01 & .97 & & & \\
\hline \multirow[t]{2}{*}{ Parent education } & .07 & .58 & & & \\
\hline & & & .04 & .04 & 1.20 \\
\hline \multicolumn{6}{|l|}{ Step 2} \\
\hline Sympathy & .01 & .97 & & & \\
\hline Depression & -.27 & .05 & & & \\
\hline Anxiety & .12 & .39 & & & \\
\hline Aggression & -.17 & .23 & & & \\
\hline English efficacy & -.03 & .80 & & & \\
\hline \multirow[t]{2}{*}{ Math efficacy } & -.20 & .14 & & & \\
\hline & & & .17 & .13 & .40 \\
\hline
\end{tabular}

nonsignificant $[\mathrm{R} 2=.17, \mathrm{~F}(9,72)=1.62, \mathrm{p}>.05]$. Adolescents who were less depressed had higher scores on parent attachment than those who were more depressed.

\section{DISCUSSION}

The primary goal of this study was to examine whether parent attachment and peer attachment were similarly related to adolescent adjustment. The present findings suggest that parent and peer relationships serve similar (although not necessarily equal) functions in terms of adolescent adjustment. This was reflected by the fact that the four groups of adolescents (those reporting high levels of security with both parents and peers, those reporting low levels of security with both parents and peers, those reporting high security with peers only, and those reporting high levels of security with parents only) differed along only one dimension in the linear discriminant func- 
tion analysis (see Fig. 1). Therefore, attachment to both parents and peers seemed to contribute similarly to adolescent adjustment, at least in terms of the adjustment indices that contributed to the discrimination among groups (i.e., sympathy, aggression, and depression).

As predicted, adolescents with strong, secure relationships to both peer and parents reported the best adjustment overall (i.e., they were the least depressed, least aggressive, and most sympathetic of the adolescents in the study). Likewise, adolescents with low levels of security with both peers and parents showed the worst adjustment (i.e., they reported the highest levels of aggression and depression and the lowest levels of sympathy). Furthermore, adolescents who had secure relationships with peers, but less secure relationships with parents, reported better adjustment (in terms of depression, aggression, and sympathy) than those who reported a secure relationship with a parent, but a less secure relationship with peers.

The results of this study support the importance of multiple attachment figures in promoting healthy adolescent adjustment. Attachment theorists have argued that having multiple secure relationships is more developmentally enhancing than having a single secure relationship (Howes, 1999) and research has generally supported this idea (for a review see Thompson, 1998). The discussion of attachment relationships in the context of multiple attachment figures raises some interesting issues about how multiple attachment relationships become integrated into a child's internal working models, especially when experiences with different attachment figures are highly divergent. Researchers have raised three possibilities as to how multiple attachment relationships become integrated into a child's internal working models. Some theorists (e.g., Bretherton, 1985) have argued for hierarchical organization in which the child's representation of the most salient attachment figure (most often the mother) is the most influential and therefore the most predictive of developmental outcomes. Others have argued (van Ijzendoorn et al., 1992) that all relationships are given equal weight and are integrated into a single representation of relationships. The third possibility is that multiple attachment relationships are not integrated but, instead, form multiple independent internal working models that are influential in different developmental domains (e.g., Suess et al., 1992). Research examining this issue is mixed (for a review see Howes, 1999) and therefore it is not clear how multiple relationships are represented by children in their working models.

The results from the present study tend to support the hierarchical organization of attachment relationships in which peers are relatively more influential on adolescent adjustment (in terms of aggression, sympathy, and depression) than parents. This was evidenced by the fact that parent and peer attachment scores had differential relationships with adolescent adjustment and that peer attachment was more significantly associated with adolescent adjustment than parent attachment. Furthermore, as already discussed parent and peer at- 
tachment scores were similarly related to the adjustment indices, discounting the idea that parent and peer attachment relationships occupied independent working models influencing different domains of development.

Although traditional attachment theory has generally promoted the influence of parents in a child's representations of relationships, the possibility arises that by adolescence, peers as attachment figures may be just as influential (if not more so as suggested by this study) in an adolescent's representations of relationships and therefore in promoting adolescent adjustment. The possibility that peers may be more influential as attachment figures in adolescence is echoed in the support literature, which has suggested that adolescents begin to rely on peers more often than parents as sources of support (Furman and Buhmester, 1992). An adolescent's increasing reliance on peers for emotional support and attachment may be the result of many factors including an adolescent's emerging autonomy from the family, a new set of concerns and interests (including sexuality) which are more easily discussed among peers, and advances in cognitive development, which may encourage adolescents to seek confidants who are similarly interested in self-exploration.

Because of the correlational nature of the study, it is not possible to confidently determine the direction of the observed effects in this study. Although it seems plausible that parent and peer attachment foster adolescent well-being, a reasonable argument can be made that the direction of the effects is reversed (i.e., well-adjusted adolescents more easily form secure relationships with parents and peers). As Bell (1968) and others (Maccoby and Martin, 1983) have argued, however, the effects are likely bidirectional with parent and peer attachment fostering adolescent adjustment and this in turn facilitating the formation and preservation of secure relationships. Longitudinal studies are needed to adequately examine the direction of the effects. In addition, by splitting our groups on the basis of mean splits on the parent and peer attachment scores, our analyses are based on relatively nonhomogeneous groups with large variations in scores. Therefore, future research might want to examine more narrowly defined extreme groups of adolescents (e.g., those with a highly secure relationship with parents and an highly insecure relationship with peers), in order better to differentiate the mixed groups (i.e., those with a secure relationship only with parents or only with peers).

It is important to note that a study using adjustment factors different from those in the present study may yield different findings. Although our findings are consistent with several other studies (e.g., Cauce et al., 1994) that have found adolescent adjustment more closely linked with support from peers than parents, they are inconsistent with other studies that have found the opposite (Barrera and Garrison-Jones, 1992; Greenberg et al., 1983). At least part of the reason for the discrepancies in studies examining parent and peer relationships and adolescent adjustment may be due to the fact that different adjustment indices were used in these studies. Thus, it is possible that parent and peer attachment may each serve to promote adjustment in specific 
domains of adolescent adjustment and the challenge of future research is to uncover the ways in which parent and peer attachment work together and separately to promote adjustment in each domain.

\section{REFERENCES}

Adams, G., and Gullotta, T. (1989). Adolescent Life Experiences, Wadsworth, Belmont, CA. Ainsworth, M. D. S. (1989). Attachments beyond infancy. Am. Psychol. 44: 709-716.

Amrsden, G., and Greenberg, M. (1987). The inventory of parent and peer attachment: Individual differences and their relationship to psychological well-being in adolescence. $J$. Youth Adolesc. 16: 427-454.

Azmitia, M., and Perlmutter, M. (1989). Social influences on children's cognition: State of the art and future directions. In Reese, H. W. (ed.), Advances in Child Development and Behavior, Vol. 22, Academic Press, New York.

Barrera, M., and Garrison Jones, C. (1992). Family and peer social support as specific correlates of adolescent depressive symptoms. J. Abnorm. Child Psychol. 20: 1-16.

Bell, R. Q. (1968). A reinterpretation of the direction of effects in studies of socialization. Psychol. Rev. 75: 81-95.

Belsky, J., and Pensky, E. (1988). Developmental history, personality, and family relationships: Toward an emergent family system. In Hinde, R. A., and Stevenson-Hinde, J. (eds.), Relationships Within Families, Clarendon, Oxford, pp. 193-217.

Blain, M., Thompson, J., and Whiffen, V. (1993). Attachment and perceived social support in late adolescence: The interaction between working models of self and others. J. Adolesc. Res. 8: 226-241.

Blyth, D. A., Hill, J. P., and Thiel, K. S. (1982). Early adolescents' significant others: Grade and gender differences in perceived relationships with familial and non-familial adults and young people. J. Youth Adolesc. 11: 425-450.

Bowlby, J. (1969/1982). Attachment and Loss, Vol. 1. Attachment, Basic, New York.

Bowlby, J. (1973). Attachment and Loss, Vol. 2. Separation: Anxiety and Anger, Basic, New York.

Bowlby, J. (1980). Attachment and Loss, Vol. 3. Loss: Sadness and Depression, Basic, New York.

Bradford, E., and Lyddon, W. J. (1993). Current parental attachment: Its relation to perceived psychological distress and relationship satisfaction in college students. J. College Stud. Dev. 34: 256-272.

Bretherton, I. (1985). Attachment theory: Retrospect and prospect. In Bretherton, I., and Waters, E. (eds.), Growing Points of Attachment Theory and Research. Monogr. Soc. Res. Child Dev. 50: 66-104 (Nos. 1-2, Serial No. 209).

Bretherton, I. (1990). Open communication and internal working models: Their role in the development of attachment relations. In Thompson, R. A. (ed.), Socioemotional Development. Nebraska Symposium on Motivation, Vol. 36, University of Nebraska Press, Lincoln, pp. 57-113.

Cauce, A. M., Mason, C., Gonzales, N., Hiraga, Y., and Liu, G. (1994). Social support during adolescence: Methodological and theoretical considerations. In Nestman, F., and Hurrelmann, K. (eds.), Social Networks and Social Support in Childhood and Adolescence, Walter de Gruyter, Berlin, pp. 89-108.

Coie, J. D., and Dodge, K. A. (1997). Aggression and antisocial behavior. In Damon, W. (ed.), Handbook of Child Psychology, 5th ed., Vol. 3. Social, Emotional, and Personality Development (N. Eisenberg, vol. ed.), Wiley, New York, pp. 779-862.

Coddington, R. D. (1972). The significance of life events as etiologic factors in the diseases of children II. J. Psychosom. Res. 16: 7-18. 
Coleman, J. (1961). The Adolescent Society: The Social Life of a Teenager and Its Impact on Education, Basic, New York.

Davis, M. H. (1983). Measuring individual differences in empathy: Evidence for a multidimensional approach. J. Person. Soc. Psychol. 25: 70-87.

Demo, D., and Acock, A. (1996). Family structure, family process, and adolescent well-being. J. Res. Adolesc. 6: 457-488.

Eisenberg, N., and Fabes, R. A. (1997). Prosocial development. In Damon, W. (ed.), Handbook of Child Psychology, 5th ed., Vol. 3. Social, Emotional, and Personality Development (N. Eisenberg, vol. ed.), Wiley, New York, pp. 701-778.

Eliot, G., and Feldman, S. (1990). Capturing the adolescent experience. In Feldman, S., and Eliot, G. (eds.), Children's Social Networks and Social Supports, Wiley, New York, pp. $119-150$.

Erikson, M., Sroufe, L. A., and Egeland, B. (1985). The relationship between the quality of attachment behavior problems in preschool in a high-risk sample. In Bretherton, I., and Waters, E. (eds.), Growing Points of Attachment Theory and Research. Monogr. Soc. Res. Child Dev. 50: 147-166 (Nos. 1-2, Serial No. 209).

Freeman, H. (1997). Who do you turn to? Parents and peers as attachment figures during adolescence. Paper presented at Society for Research in Child Development, Washington, DC, Apr.

Furman, W., and Buhmester, D. (1992). Age and sex differences in perceptions of networks and personal relationships. Child Dev. 63: 103-115.

Garneski, N., and Diekstra, R. (1996). Perceived social support from family, school, and peers: Relationship with emotional and behavioral problems among adolescents. J. Am. Acad. Child Adolesc. Psychiatry 35: 1657-1664.

Greenberg, M., Siegal, J., and Leithch, C. J. (1983). The nature and importance of attachment relationships to parents and peers during adolescence. J. Youth Adolesc. 12: 373-386.

Hazan, C., and Shaver, P. (1987). Romantic love conceptualized as an attachment process. $J$. Person. Soc. Psychol. 52: 511-524.

Howes, C. (1999). Attachment relationships in the context of multiple caregivers. In Cassidy, J., and Shaver, P. (eds.), Handbook of Attachment, Guilford, New York, pp. 671-687.

Kobak, R. R., and Cole, H. (1994). Disorders and dysfunctions of the self. In Cicchetti, D., and Toth, S. (eds.), Rochester Symposium on Developmental Psychopathology, Vol. 5. University of Rochester Press, Rochester, NY, pp. 267-297.

Kobak, R. R., and Sceery, A. (1988). Attachment in late adolescence: Working models, affect regulation, and representations of self and others. Child Dev. 59: 135-146.

Kovacs, M., and Beck, A. T. (1977). An empirical and clinical approach towards defining childhood depression. In Schulterbrandt, J. G., and Rasbin, A. (eds.), Depression in Childhood: Diagnosis, Treatment and Conceptual Models, Raven Press, New York, pp. $1-25$.

Kuczynski, L., Marshall, S., and Schell, K. (1997). Value socialization in a bidirectional context. In Grusec, J. El., and Kuczynski, L. (eds.), Parenting Strategies and Children's Internalization of Values: A Handbook of Theoretical and Research Perspectives, Wiley, New York.

LaFreniere, P. J., and Sroufe, L. A. (1985). Profiles of peer competence in the preschool: Interrelations between measures, influence of social ecology, and relation to attachment history. Dev. Psychol. 21: 56-69.

Laible, D. J., and Thompson, R. A. (1998). Attachment and emotional understanding in preschool children. Dev. Psychol. 34: 1038-1045.

Lapsley, D., Rice, K., and FitzGerald, D. (1990). Adolescent attachment, identity, and adjustment to college: Implications for the continuity of adaptation hypothesis. J. Counsel. Dev. 68: 561-565. 
Laursen, B., and Collins, W. (1994). Interpersonal conflict during adolescence. Psychol. Bull. 115: 197-209.

Maccoby, E., and Martin, J. (1983). Socialization in the context of the family: Parent-child interaction. In Heatherington, E. (ed.), Mussen Manual of Child Psychology, Vol. 4, 4th ed., Wiley, New York, pp. 1-102.

Melby, J. and Cogner, R. (1996). Parental behaviors and adolescent academic performance: A longitudinal analysis. J. Res. Adolesc. 6: 113-137.

Piaget, J. (1965/1935). The Moral Judgment of the Child, Routledge \& Kegan Paul, London.

Reynolds, C. R., and Richmond, B. O. (1985). The Revised Childhood Manifest Anxiety Scale (RCMAS Manual), Western Psychological Services, Los Angeles.

Ryan, R., Stiller, J., and Lynch, J. (1994). Representations of relationships to teachers, parents, and friends as predictors of academic motivation and self-esteem. J. Early Adolesc. 14: 226-249.

Sroufe, L. A. (1983). Infant-caregiver attachment and patterns of adaptation in preschool: The roots of maladaptation and competence. In Perlmutter, M. (ed.), Development and Policy Concerning Children with Special Needs. Minnesota Symposia on Child Psychology, 16, Erlbaum, Hillsdale, NJ, pp. 41-83.

Suess, G. J., Grossman, K. E., and Sroufe, L. A. (1992). Effects of infant attachment to mother and father quality of adaptation in preschool: From dyadic to individual organization of self. Int. J. Behav. Dev. 15: 43-65.

Thompson, R. (1998). Early sociopersonality development. In Damon, W. (ed.), Handbook of Child Psychology, 5th ed., Vol. 3. Social, Emotional, and Personality Development (N. Eisenberg, vol. ed.), Wiley, New York, pp. 25-104.

van Ijzendoorn, M. H., Sagi, A., and Lambermon, M. W. E. (1992). The multiple caretaker paradox: Data from Holland and Israel. In Pianta, R. C. (ed.) Beyond the parent: The role of other adults in children's lives (New Directions for Child Development Series, No. 57), Jossey-Bass, San Francisco, pp. 5-24.

Weinberger, D. A. (1991). Social-emotional adjustment in older children and adults: I. Psychometric properties of the Weinberger Adjustment Inventory, Unpublished manuscript, Case Western Reserve University, Columbus, OH.

Youniss, J. (1985). Parents and Peers in Social Development: A Sullivan-Piaget Perspective, University of Chicago Press, Chicago. 